\title{
Urban traffic-derived nanoparticulate matter reduces neurite outgrowth via TNFa in vitro
}

\author{
Hank Cheng ${ }^{1,3}$, David A. Davis ${ }^{1}$, Sina Hasheminassab², Constantinos Sioutas², Todd E. Morgan
} and Caleb E. Finch ${ }^{1,3^{*}}$

\begin{abstract}
Background: The basis for air pollution-associated neurodegenerative changes in humans is being studied in rodent models. We and others find that the ultrafine particulate matter (PM) derived from vehicular exhaust can induce synaptic dysfunction and inflammatory responses in vivo and in vitro. In particular, a nano-sized subfraction of particulate matter (nPM, PM0.2) from a local urban traffic corridor can induce glial TNFa production in mixed glia (astrocytes and microglia) derived from neonatal rat cerebral cortex.
\end{abstract}

Methods: Here, we examine the role of TNFa in neurite dysfunctions induced by nPM in aqueous suspensions at $12 \mathrm{\mu g} / \mathrm{ml}$. First, we show that the proximal brain gateway to nPM, the olfactory neuroepithelium (OE), rapidly responds to nPM ex vivo, with induction of TNFa, activation of macrophages, and dendritic shrinkage. Cell interactions were further analyzed with mixed glia and neurons from neonatal rat cerebral cortex.

Results: Microglia contributed more than astrocytes to TNFa induction by nPM. We then showed that the threefold higher TNFa in conditioned media (nPM-CM) from mixed glia was responsible for the inhibition of neurite outgrowth by small interfering RNA (siRNA) TNFa knockdown and by TNFa immunoneutralization. Despite lack of TNFR1 induction by nPM in the OE, experimental blocking of TNFR1 by TNFa receptor blockers restored total neurite length.

Conclusions: These findings implicate microglia-derived TNFa as a mediator of nPM in air pollution-associated neurodegenerative changes which alter synaptic functions and neuronal growth.

Keywords: Air pollution, Nanoparticulate matter, Olfactory neuroepithelium, TNFa, Neurite outgrowth, Cell culture, Microglia

\section{Background}

Air pollution epidemiology has traditionally focused on cardiovascular and respiratory outcomes. These adverse associations have been extended to show the acceleration of cognitive decline of elderly communitybased populations [1-5] and neurodevelopmental impairments of children [6,7]. The causes of cognitive impairment are being analyzed in rodent and cell models, which implicate neuroinflammatory responses

\footnotetext{
* Correspondence: cefinch@usc.edu

'Davis School of Gerontology, University of Southern California, Los Angeles, CA 90089, USA

${ }^{3}$ USC Dornsife College, University of Southern California, Los Angeles, CA 90089, USA

Full list of author information is available at the end of the article
}

to urban air pollutants [8-11]. Specifically, we and others observed that the ultrafine size class of air pollution PM0.2 $(<0.2 \mu \mathrm{m}$ diameter $)$ activated microglia and induced TNF $\alpha$ and IL-1, among other inflammatory responses [10, 12-14]. This evidence supports findings of increased microglial activation and white matter hyperintensities in small postmortem samples of children from a highly polluted Mexican city [7, 15] and in the association of white matter loss in older human adults in an MRI analysis of the WHIMS cohort of US women [16].

We focus on traffic-derived ultrafine PM, which consistently shows higher toxicity than larger PM in vivo and in vitro $[17,18]$, in neonatal rodents. Artificial ultrafine 
PM is rapidly transported after inhalation into the brain via the olfactory pathway $[19,20]$. Within the ultrafine $\mathrm{PM}$, we examined a subfraction eluted from filters into aqueous suspension for its neurotoxicity and proinflammatory activity $[10,11]$. This subfraction is designated as nano-sized PM (nPM) to distinguish it from the total ultrafine PM and is depleted in black carbon and water-insoluble organics (Table 1) [10]. The nPM fraction is highly active in vitro and in vivo after re-aerosolization, with free radical EPR signals that persisted $\geq 30$ days after initial collection. Notably, ozone and other gaseous pollutants with epidemiological cognitive associations $[2,21]$ are absent from filter-collected nPM. In rodent cell models, nPM has both direct and indirect effects on neuronal viability and neurite outgrowth [10]. Because TNF $\alpha$ is induced by chronic inhalation of ultrafine PM $[8,22]$ and because TNF $\alpha$ can alter neurite outgrowth [23-25], we further evaluated the role of TNFo in rapid brain responses to nPM. We first investigated the olfactory epithelium (OE), since little is known about the initial cellular responses of the olfactory gateway to urban traffic-derived ultrafine (or, equivalently) nPM. Based on the precedent of ex vivo OE incubation from OE biopsies [26, 27], we developed an ex vivo model for incubation of the intact $\mathrm{OE}$ within neonatal mouse nasal cavities with nPM suspensions. In addition, using glia and neurons derived from neonatal cerebral cortex, we analyzed mechanisms by which nPM-induced TNF $\alpha$ inhibits neurite outgrowth.

\section{Methods}

\section{nPM collection and transfer into aqueous suspension}

Nano-sized particulate matter (nPM; $<0.2 \mu \mathrm{m}$ in diameter) was collected on Teflon filters by a HighVolume Ultrafine Particle (HVUP) Sampler [28] at $400 \mathrm{l} / \mathrm{min}$ flow in urban Los Angeles, downwind from the local I-110 Freeway [10]. These samples are a mix

Table 1 Composition of nPM

\begin{tabular}{|c|c|c|c|}
\hline & $\begin{array}{l}\text { Ambient } \\
\text { nPM (\%) }\end{array}$ & $\begin{array}{l}\text { Eluted nPM } \\
\text { (\%) }\end{array}$ & $\begin{array}{l}\% \text { ambient in } \\
\text { eluted nPM }\end{array}$ \\
\hline Black carbon & 13 & 1 & 7 \\
\hline $\begin{array}{l}\text { Organic carbon, } \\
\text { water soluble }\end{array}$ & 32 & 34 & 100 \\
\hline \multicolumn{4}{|l|}{$\begin{array}{l}\text { Organic carbon, } \\
\text { water insoluble }\end{array}$} \\
\hline Hopanes-steranes & 0.012 & 0.001 & 8.5 \\
\hline Organic acids & 0.097 & 0.009 & 9 \\
\hline $\begin{array}{l}\text { Polyaromatic } \\
\text { hydrocarbons }\end{array}$ & 0.02 & $\begin{array}{l}\text { Not } \\
\text { detected }\end{array}$ & 0 \\
\hline Metals (Cu, Fe, Ni, V) & & & $>90$ \\
\hline
\end{tabular}

Content of black carbon, water-soluble and water-insoluble organic carbons, and metals in ambient nPM compared with eluted filter-trapped nPM. Percent recovery of ambient $\mathrm{nPM}$ in eluted samples was calculated to show efficiency of transfer. Data derived from [10] of fresh ambient PM, mostly from vehicular traffic emissions and secondary aerosols [29, 30]. The nPM samples were collected continuously during July-Sept. 2010 and Nov. 2011-Feb. 2012; these pooled samples approximate the annual average composition of nPM near the I-110 corridor [31]. The filter-trapped dried $\mathrm{nPM}$ were eluted by sonication into deionized water. The nPM comprise $20 \%$ by mass of ambient PM2.5. Water-soluble metals and organic compounds were efficiently transferred (Table 1). Relative to the total filter-trapped ultrafines (PM0.2), the nPM subfraction eluted into aqueous phases is depleted in black carbon and water-insoluble organic compounds. nPM suspensions $(350 \mu \mathrm{g} / \mathrm{ml})$ were stored at $-20{ }^{\circ} \mathrm{C}$. For controls of nPM extracts, fresh sterile filters were sham-extracted.

\section{Animals}

C57BL/6J mice were purchased from The Jackson Laboratory (Sacramento, CA, USA) for breeding and pregnant Sprague Dawley rats from Harlan Labs (Livermore, CA, USA). Animals were maintained following $\mathrm{NIH}$ guidelines, approved by the USC Institutional Animal Care and Use Committee (IACUC). Animals were euthanized by cervical dislocation after anesthesia by isoflurane or $\mathrm{CO}_{2}$.

\section{Nasal cavity ex vivo incubation}

P3 mice (both sexes) were anesthetized and decapitated; the nasal bone was removed to reveal the nasal cavity. The entire nasal cavity including the snout intact was removed in the gross. Nasal cavities were incubated with $12 \mu \mathrm{g} / \mathrm{ml} \mathrm{nPM}$ in artificial cerebral spinal fluid (CSF) for $2 \mathrm{~h} / 37^{\circ} \mathrm{C}$. After incubation, the $\mathrm{OE}$ was peeled from the nasal cavity for quantitative polymerase chain reaction (qPCR) or immunohistochemistry. Mice were chosen for these experiments because their smaller size facilitates slide preparation and obviates decalcification.

\section{Cell culture}

Mixed glia were originated from the cerebral cortex of postnatal day 3 (P3) rats (both sexes). Primary glia were grown in Dulbecco's modified Eagle's medium/Ham's F12 50/50 Mix (DMEM F12 50/50) supplemented with $10 \%$ fetal bovine serum (FBS) and $1 \%$ L-glutamine in a humidified incubator $\left(37{ }^{\circ} \mathrm{C} / 5 \% \mathrm{CO}_{2}\right)$ [32]. After culture for 2.5 weeks, their composition was 3:1 astrocytes:microglia. Microglia were isolated by shaking for $4 \mathrm{~h} /$ $37^{\circ} \mathrm{C}$. Embryonic day 18 (E18) rat cortical neurons were originated at 15,000 neurons $/ \mathrm{cm}^{2}$ on poly-D-lysine-coated coverslips in DMEM supplemented with B27 (Invitrogen, Grand Island, NY).

For in vitro exposure, mixed glia were trypsinized and replated in six-well plates at $1 \times 10^{6}$ cells/well and grown overnight. Secondary cultures of mixed glia were treated with $\mathrm{nPM}$ aqueous suspensions $(12 \mu \mathrm{g} / \mathrm{ml})$ diluted in 
neuronal media for $24 \mathrm{~h}$ before assay. This dose consistently induced glial TNF $\alpha$ and IL- $1 \alpha$ messenger RNA (mRNA) [10]. The resulting conditioned media (CM) was collected and centrifuged $(10,000 \mathrm{~g} / 10 \mathrm{~min})$ to remove residual cells. For small interfering RNA (siRNA) experiments, mixed glia were treated with siRNA (Silencer Negative Control No. 1 siRNA, AM4611; Ambion, Austin, TX) or TNF $\alpha$ siRNA (AM16708, Ambion). Scrambled and TNF $\alpha$ siRNAs were mixed with a siPORT NeoFX transfection agent (Ambion) to $50 \mathrm{nM}$. Mixed glia were grown for $24 \mathrm{~h}$ post transfection and then treated with nPM or vehicle before plating onto E18 neurons. Immunoneutralization of TNFo used $20 \mu \mathrm{g} / \mathrm{ml}$ antibody (MAB510; R\&D Systems, Minneapolis, MN); TNF receptor activity was inhibited by TNFR1/2 blocking peptide (E-20, L-20; SCBT, Dallas, TX) at $5 \mu \mathrm{g} / \mathrm{ml}$ before CM application. Rats were used for in vitro experiments, following our prior studies [10] and the better yields of microglia than from mice.

\section{Quantitative polymerase chain reaction}

Total cellular RNA was extracted using TRI reagent (Sigma, St. Louis, MO). cDNA was prepared from $1 \mu \mathrm{g}$ of RNA by Superscript III RT kit (Invitrogen, Carlsbad, CA) and analyzed by qPCR with appropriate primers for both mouse and rat for $\mathrm{Ct}$ (threshold cycle) values. Genes examined by qPCR include TNF $\alpha$ (forward: 5' CGTCAGCCGATTTG CTATCT 3'; reverse: 5' CGGACTCCGCAAAGTCTAAG 3') (CT range 26-30), Ibal (forward: 5' CCTGATTGGAGGTGGATGTCAC 3'; reverse: 5' GGCTCACGACT GTTTCTTTTTTCC 3') (CT range 25-26), IL-1 $\alpha$ (forward: 5' TCGGGAGGAGACGACTCTAA 3'; reverse: 5' GTGCACCCGACTTTGTTCTT 3') (CT range 29-31), GFAP (forward: 5' CCAAGCCAAACACGAAGCTAA 3'; reverse: 5' AGGAATGGTGATGCGGTTTTC 3') (CT range 30-31), iNOS (forward: 5' CATTGGAAGTGAAG CGTTTCG 3'; reverse: 5' CAGCTGGGCTGTACAAAC CTT 3') (CT range 27-29), TNFR1 (forward: 5' GGGCA CCTTTACGGCTTCC 3'; reverse: 5' GGTTCTCCTTACAGCCACACA 3') (CT range 22-23), TNFR2 (forward: 5' CAGGTTGTCTTGACACCCTAC 3' reverse: 5' GCACAGCACATCTGAGCCT 3') (CT range 25-26), BIIItubulin (forward: 5' CGCACGACATCTAGGACTGA 3'; reverse: 5' TGAGGCCTCCTCTCACAAGT 3') (CT range 19-20), and rGAPDH (forward: 5' AGACAGCCGCATC TTCTTGT 3'; reverse: 5' CTTGCCGTGGGTAGAGTCAT 3') (CT range 16-17). Data were normalized to GAPDH and quantified as $\Delta \Delta \mathrm{Ct}$.

\section{ELISA}

CM from nPM-treated glia was sampled after $24 \mathrm{~h}$ of exposure and analyzed for TNFa by solid phase sandwich ELISA (BD Biosciences, San Jose, CA).

\section{Immunohistochemistry}

The OE and olfactory bulb of P3 neonatal mice were fixed with $4 \%$ paraformaldehyde in phosphate buffered saline (PBS) pH 7.4. Specimens were immersed in $10 \%$ sucrose/PBS pH 7.4, then $30 \%$ sucrose/PBS pH 7.4 at $4{ }^{\circ} \mathrm{C}$, then embedded in optimal cutting temperature compound (OCT; Fisher Scientific, Waltham, MA) before transverse cryostat sectioning $(18 \mu \mathrm{m})$. Antigen retrieval was performed by submerging slides in $10 \mathrm{mM}$ sodium citrate buffer and microwaving for $3 \mathrm{~min}$. Tissue was permeabilized with $1 \% \mathrm{NP}-40 / \mathrm{PBS}$ and blocked with $5 \%$ BSA, then probed with antibodies specific for the Olfactory Marker Protein of olfactory sensory neurons (OMP 1:100; SCBT, Dallas, TX), BIII-tubulin (1:400; Sigma Chemical Co., St. Louis, MO), astrocytes (GFAP 1:400; Sigma), and microglia (Iba1 1:200, Wako). Immunofluorescence was visualized with Alexa Fluor 488 or 594 antibodies (1:400; Molecular Probes).

\section{Microscopy}

Fluorescent images were analyzed with a Nikon Eclipse TE300 microscope (Nikon, Melville, NY). One hundred neurons were selected from a distribution of nine images per coverslip for analysis.

\section{Neurite outgrowth assays}

After exposure to glial conditioned media, E18 neurons were fixed in $4 \%$ paraformaldehyde and immunostained with anti-BIII-tubulin (1:400). Neurites were visualized by F-actin with Rhodamine phalloidin (1:50; Molecular Probes, Carlsbad, CA). Images were analyzed for neurite length, density, and number by NeuronJ of ImageJ software; soma size was determined by the Neurphology plugin of ImageJ. Only neurons with neurites fully visible were analyzed. Neurite density was assayed as total BIII-tubulin fluorescence after skeletonizing. Axons were identified as the longest neurite [33].

\section{Image analysis}

The olfactory sensory neuron (OSN) dendritic layer of the $\mathrm{OE}$ was assessed by NeuronJ plugin of ImageJ in 20 evenly spaced regions in the nasal septum and ethmoturbinates. The dendritic layer thickness was defined as the distance between the OSN cell body and the outer edge of the sensory dendrites in the nasal cavity.

\section{Statistical analysis}

GraphPad Prism Version 5 (Graph Pad, La Jolla, CA) was used. Single and multiple comparisons used Student's $t$ test (unpaired) and ANOVA/Tukey's multiple comparison post-test, respectively. Level of significance alpha $=0.05$. 


\section{Results}

$\mathrm{nPM}$ rapidly induced TNFa in olfactory neuroepithelium ex vivo

First, we characterized the OE cell populations which are incompletely described for neonatal mice. Figure 1a represents the main anatomic features of the nasal cavity. The OE contains well differentiated OSN ( $\beta$ III-tubulin-immunopositive) with perikarya on the inner face of the $\mathrm{OE}$ (Fig. 1b); the OSN dendrites extend into the mucosa lining the turbinate space as a layer distinct from their perikarya; axon bundles of the OSN project through the cribriform plate to the olfactory bulb $(\mathrm{OB})$, identified by immunostaining for the OSN-specific Olfactory Marker Protein (not shown). Macrophages (Iba1-immunopositive) defined a dense layer in the lamina propria, sharply demarcated from their lower density in the adjacent OSN layer/lamina propria (Fig 1c). GFAP immunostaining for astrocytes was not above background in the $\mathrm{OE}$; in contrast, the $\mathrm{OB}$ has numerous GFAP-positive astrocytes (not shown).

As an ex vivo model for the initial contact of brain with $\mathrm{nPM}$, the nasal cavities of neonatal mice were incubated with nPM suspensions. Ex vivo nasal cavities were incubated with $12 \mu \mathrm{g} / \mathrm{ml} \mathrm{nPM}$ for $2 \mathrm{~h}$, conditions that induced TNF $\alpha$ in mixed glial cultures [10]. The OSN responded with shrinkage of the dendritic layer in the OE septal zone by $10 \%$ across the dendritic length

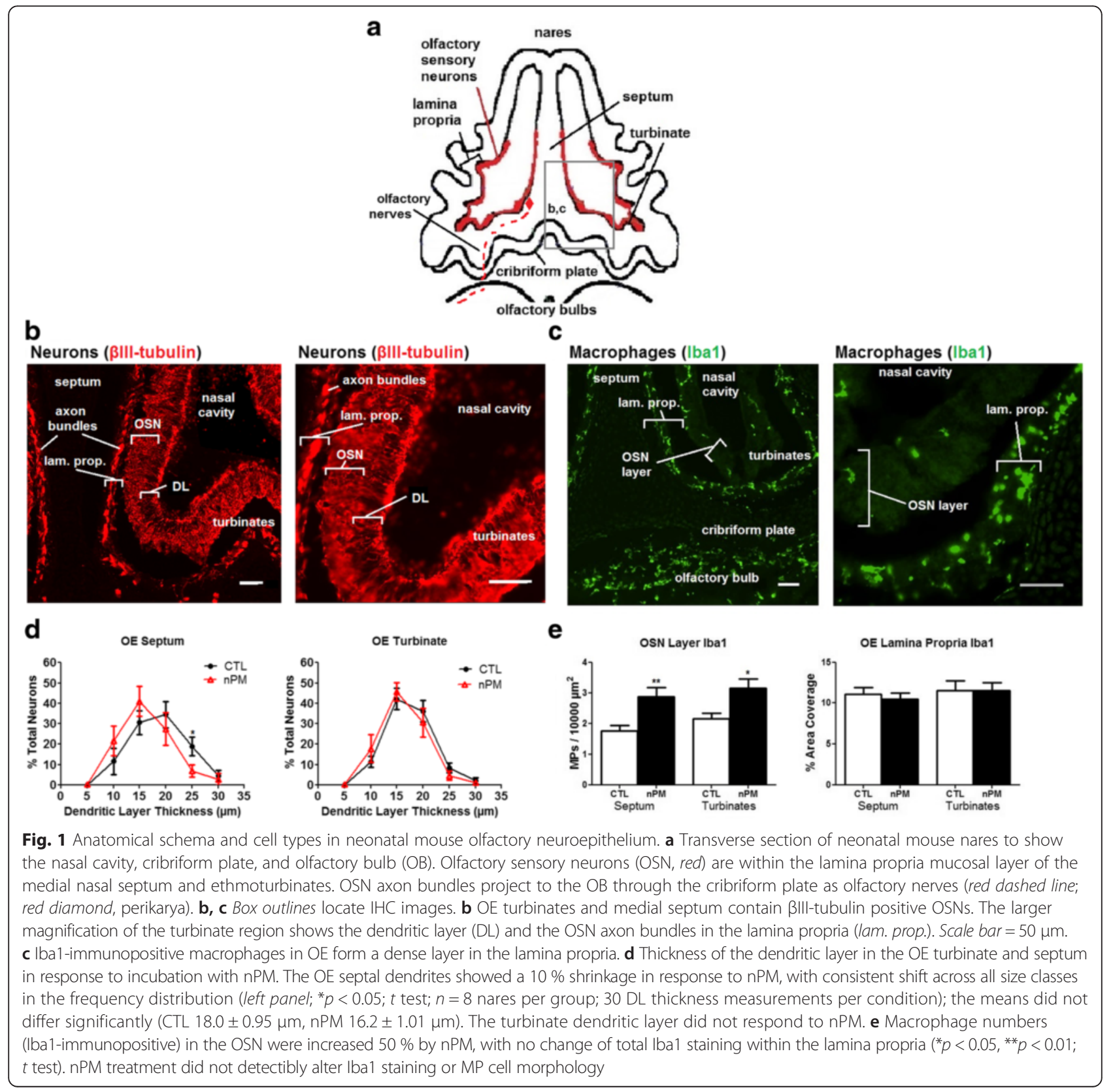


frequency distribution; turbinate zone dendrites had smaller responses (Fig. 1d). Macrophages also responded, with a $50 \%$ increase in Iba1-immunopositive cells in the OSN layer (Fig. 1e). By qPCR, we found increased levels of inflammation-related mRNAs in the OE including $45 \%$ increase of TNF $\alpha$ mRNA and $20 \%$ increase of Iba1 mRNA (Fig. 2a, c), with trends for increased IL-1 $\alpha$ and TNFR1 (Fig. 2b, d); definitive non-changers included iNOS, TNFR2, and BIII-tubulin mRNA (not shown). GFAP mRNA was below reliable CT values (see Fig. 2 legend), consistent with background GFAP immunostaining in the OE noted above. Because TNF $\alpha$ inhibits neurite outgrowth in vitro and in vivo [24, 34], we hypothesized that TNF $\alpha$ secreted by OE macrophages is an initial event in neurite shrinkage.

\section{nPM-induced TNFa in both astrocytes and microglia}

To facilitate analysis of relationships between the glial secretion of TNF $\alpha$ and neurite length, we used mixed glial cultures from the cerebral cortex of neonatal rat, in which TNF $\alpha$ mRNA was readily induced by nPM (Fig. 3a). The dose response reported for a prior sample of nPM collected in January 2009 [10] was closely matching. Extending these findings, exposure to nPM at
$12 \mu \mathrm{g} / \mathrm{ml}$ for $24 \mathrm{~h}$ induced TNF $\alpha$ mRNA $>3$-fold in cultures of separated microglia or astrocytes (Fig. 3b). Microglial responses were larger than astrocytes by the TNF $\alpha / G A P D H$ ratio. The CM from mixed glia that were exposed to nPM (nPM-CM) showed corresponding increases in TNF $\alpha$ protein, again with greater increases from microglia (Fig. 3c). Cell levels of TNF $\alpha$ mRNA and of CM TNF $\alpha$ protein were positively correlated $\left(r^{2}=0.28\right.$, not shown). Because glial gene expression can depend on contact between microglia and astrocytes, e.g., apolipoprotein $\mathrm{E}$ and apolipoprotein $\mathrm{J}[35,36]$, it is notable that the TNF $\alpha$ GAPDH in separated astrocytes (0.0048) and microglia (0.0145) approximated that of mixed glia (0.0755) after adjusting for their relative proportions in mixed glia. Despite their minority as $\sim 25 \%$ of the cells in mixed glia, microglia contributed $60 \%$ of the TNFo protein in $\mathrm{CM}$.

\section{Conditioned media from nPM-treated astrocytes and microglia reduce neurite outgrowth}

nPM-CM from mixed glia or enriched astrocytes and microglia was analyzed for neurotrophic activity by neurite outgrowth of E18 rat cerebral cortex neurons and supported less neurite outgrowth, assessed by

\section{a}

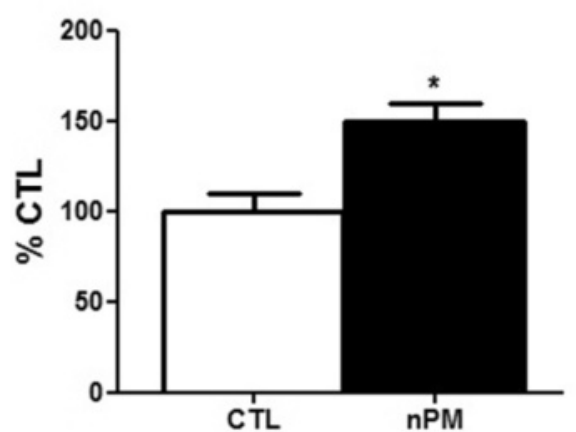

C

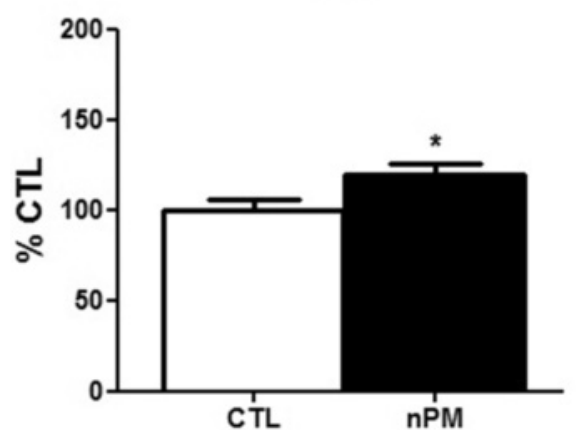

b

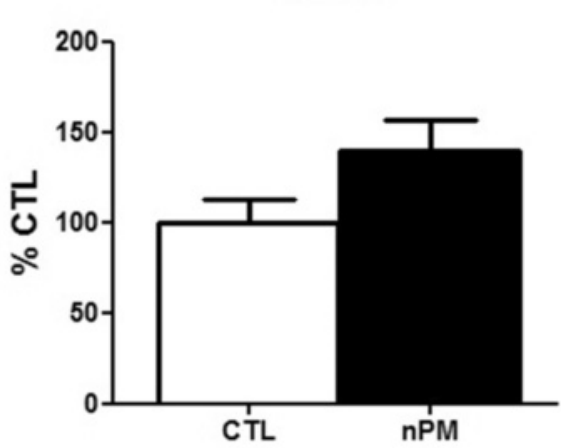

d

IL-1 $\alpha$

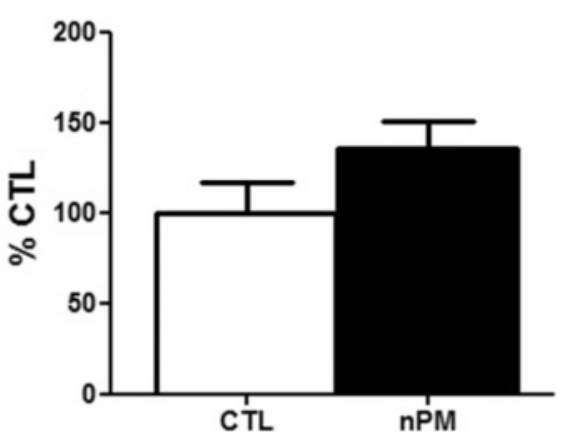

Fig. 2 nPM rapidly induced cytokine mRNA in ex vivo olfactory neuroepithelium. a, c Incubation with nPM (12 $\mu \mathrm{g} / \mathrm{ml}, 2 \mathrm{~h})$ increased TNFa mRNA by $50 \%$ and Iba1 by $20 \%\left({ }^{*} p<0.05 ; t\right.$ test; $\left.n=7\right)$. b, $\mathbf{d} I L-1$ a and TNFR1 $(p=0.079,0.058$, respectively). GFAP mRNA was below reliable PCR values (OE Ct $>30$ vs cerebral cortex $\mathrm{Ct}<24$, positive control) 

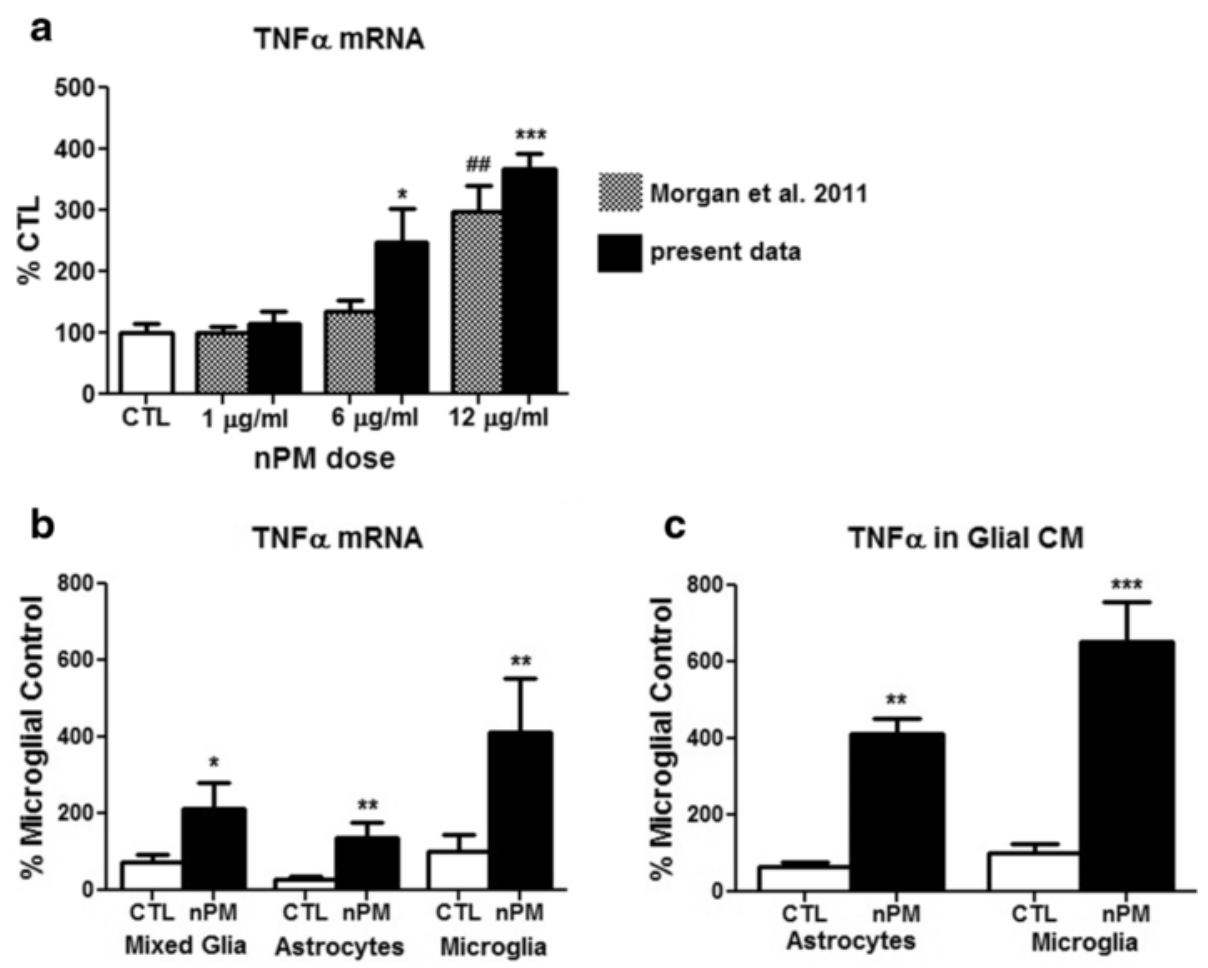

Fig. 3 Mixed glia exposed to nPM: increased TNFa mRNA and protein. a TNFa mRNA was significantly induced by 6 and $12 \mu \mathrm{g} / \mathrm{ml} \mathrm{nPM}$. $\left({ }^{*} p<0.05\right.$, $\# \# p<0.01,{ }^{* * *} p<0.001$; ANOVA with Tukey's post-test; $n=6$ ). Prior data (cross-hatched) was shown to document equivalent activity of different samples of nPM collected at the same site on different years (2009 vs 2010-2011). b TNFa mRNA in mixed glia, enriched astrocytes, and enriched microglia treated with nPM were increased by $>3$-fold vs CTL: microglia $>$ mixed glia $>$ astrocytes $\left({ }^{*} p<0.05,{ }^{*} p<0.01 ; t\right.$ test; $n=9$ ). Treated microglia had the lowest base Ct values. c TNFa protein in CM was increased by fivefold vs CTL (** $p<0.01$; ${ }^{* *} p<0.001 ; t$ test; $n=6$ )

length: mixed glia, $-20 \%$; astrocytes, $-15 \%$; microglia, $-30 \%$ (total neurite length per neuron) (Fig. $4 \mathrm{a}-\mathrm{c}$ ) with a trend for fewer neurites (Fig. 4d). Neurons grown in microglial CM had lower baseline neurite outgrowth (Fig. 4c).

\section{Inhibiting or reducing TNFa in the CM rescued neurite outgrowth}

To define the role of TNF $\alpha$ in $\mathrm{nPM}-\mathrm{CM}$ in neurite outgrowth inhibition, mixed glia were transfected with TNF $\alpha$ siRNA, which reduced TNF $\alpha$ mRNA by $70 \%$ vs scrambled siRNA control (not shown). CM from TNF $\alpha$ siRNA-treated glia (also nPM exposed) rescued neurite outgrowth, total neurite density, and axon length (Fig. 5a, c, e), but without altering total neurite number or the area of neuronal perikarya (Fig. 5b, d). The frequency distribution of total neurite lengths showed consistent shortening: $35 \%$ of neurons grown in nPM or $\mathrm{nPM}+$ scrambled siRNA glial media had total neurite lengths $<100 \mu \mathrm{m}$ vs $20 \%$ in control or TNF $\alpha$ silenced conditions. Only $10 \%$ of these neurons had total neurite lengths $>200 \mu \mathrm{m}$ vs $20 \%$ of control and siRNA treatments (Fig. 5f).
The role of TNFa in the nPM-CM was further shown by immunoneutralization with anti-TNF $\alpha$ antibodies, which also rescued neurite outgrowth (Fig. 6).

\section{Blocking TNFR1 in neurons reduced the CM effect on neurite outgrowth}

The role of TNF $\alpha$ receptors was evaluated by "blocking peptides" (antibodies) to the $\mathrm{C}$ terminus of their respective TNFRs. Neurons were pre-incubated with blocking peptides before application of nPM-CM. The antiTNFR1 peptide restored total neurite length to control levels, while anti-TNFR2 had no effect on the nPM-CM inhibition (Fig. 7a). Growth cones were increased $30 \%$ only by anti-TNFR1 (Fig. 7b, c), with $10 \%$ fewer neurites $<100 \mu \mathrm{m}$ vs nPM-CM-treated cultures (data not shown).

\section{Discussion}

These studies further document the role of glial TNF $\alpha$ in neuroinflammatory responses to air pollution PM that modify neuronal function. In particular, we studied nPM, which are a subfraction of urban PM2.5 ("Methods" section) that epidemiological studies have associated with neurodevelopmental dysfunctions from 


\section{a}

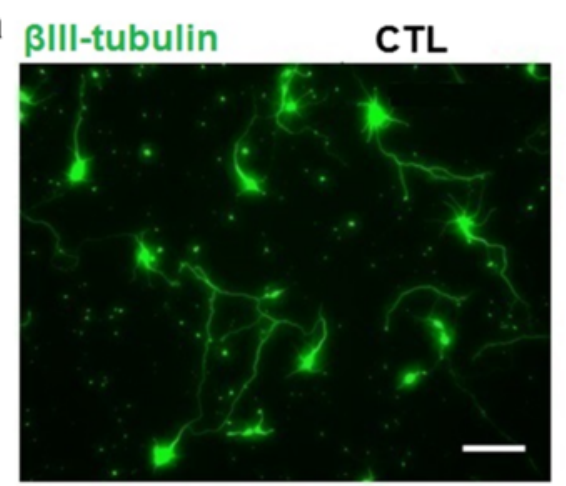

C

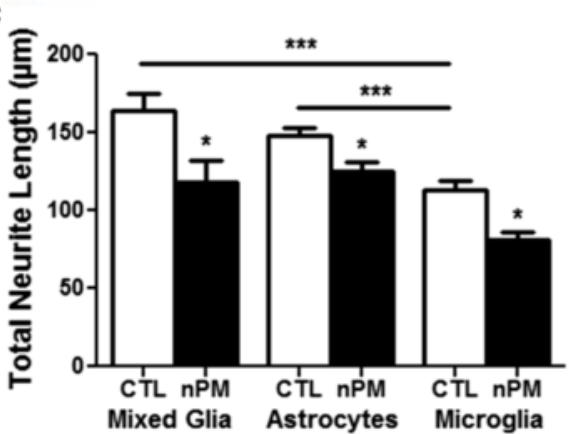

b $_{\beta}$ III-tubulin

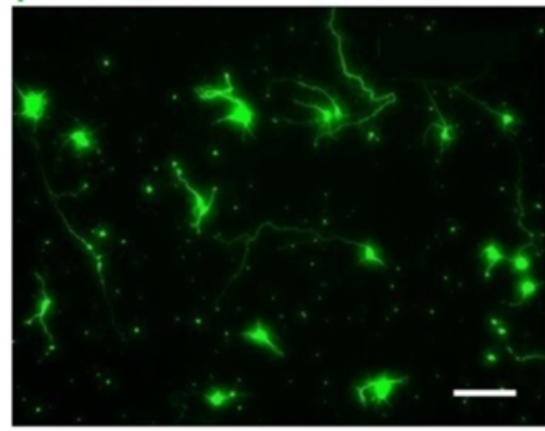

d

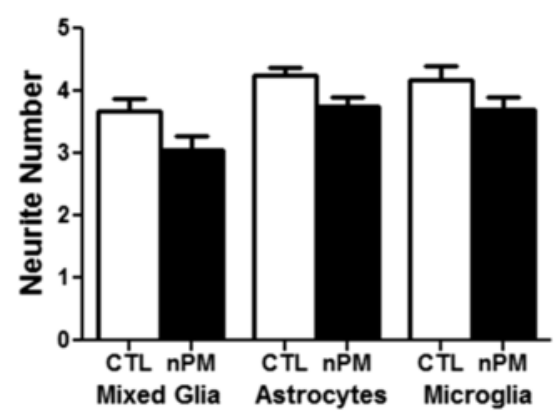

Fig. $4 \mathrm{CM}$ from glia treated with nPM decreased neurite outgrowth. a Neurons treated with mixed glial CM; $\beta I I I-t u b u l i n ~ I H C ; ~ s c a l e ~ b a r=40 ~ \mu m$. b Neurons treated with CM from nPM-treated mixed glia; $\beta$ III-tubulin IHC; scale bar = $40 \mu \mathrm{m}$. c Addition of CM from nPM-treated mixed glia, astrocytes, or microglia decreased neurite length by 20,15 , and $30 \%$, respectively, vs controls. Microglial CM controls had lower baseline neurite outgrowth compared to mixed glia CM and astrocyte CM. ( ${ }^{*} p<0.05,{ }^{* *} p<0.001$; ANOVA with Tukey's post-test; $n=100$ neurons). $\mathbf{d}$ Neurite number showed trend for decrease by addition of CM from nPM-treated mixed glia, astrocyte, or microglia (n.S., ANOVA)

pre- and early childhood exposure [37, 38]. Rodent models include exposure of pregnant rats to nPM, which altered neonatal neuronal maturation [39] and exposure of early postnatal mice to ultrafine PM, which caused ventriculomegaly and glial activation [22]. For inflammatory responses, we focused on TNF $\alpha$ because of its consistent elevation in rodent models of air pollution [8, 10, 40-42] as well as in postmortem human brains from a highly polluted megacity [15]. In vitro activities of nPM include induction of TNF $\alpha$ in mixed glia from cerebral cortex and reduced neurotrophic support by the $\mathrm{CM}$ of mixed glia exposed to nPM [10]. We also document the stability of $\mathrm{nPM}$ activity to induce TNFo, in which the dose response was nearly identical, despite collection from the same site on different years.

We hypothesized that glial TNF $\alpha$ was a mediator of these CM effects because TNF $\alpha$ in vitro inhibits neurite outgrowth [24, 34] with growth cone collapse [43] and inhibits astrocytic neurotrophic support [44]. Before further analysis of cerebral cortex glia, we investigated if TNF $\alpha$ induction by air pollution PM extended to the OE which is the initial site of exposure of inhaled air pollutants from which olfactory neurons project into the brain. Importantly, besides the acute inflammatory responses of TNF $\alpha$ and macrophage activation, the OE expresses high levels of phase I and phase II detoxifying enzymes, e.g., cytochrome P450 (CYP) isoforms and glutathione S-transferases (GST) $[45,46]$, which may mediate detoxifying environmental pollutants.

We developed an ex vivo model for the initial impact of air pollution on olfactory neurons, in which the neonatal mouse nose is incubated with aqueous suspensions of nPM. During ex vivo incubation with nPM, the neonatal OE showed rapid shrinkage of the OSN dendritic layer concurrently with induction of TNF $\alpha$ and macrophage activation in the OE. We hypothesized that olfactory neuron dendritic regression was driven by TNF $\alpha$ from macrophages in the OE. This is supported by another model of olfactory damage, where TNF $\alpha$ was shown to inhibit $\mathrm{OE}$ regeneration [47]. We further tested this hypothesis with primary glial cultures from the neonatal mouse cerebral cortex as discussed below.

In rodent models, nPM cross from the nose into the brain by undefined transport processes which are presumed to include the projections of OSN axons that synapse in the main olfactory bulb $[19,20]$. Studies with different artificial ultrafine PM observed that inhaled [19] or nasally instilled [20] PM reached the forebrain and cerebellum as well as the OB within $24 \mathrm{~h}$ [48]. The passage of $\mathrm{nPM}$ from the nares beyond the $\mathrm{OB}$ into the 


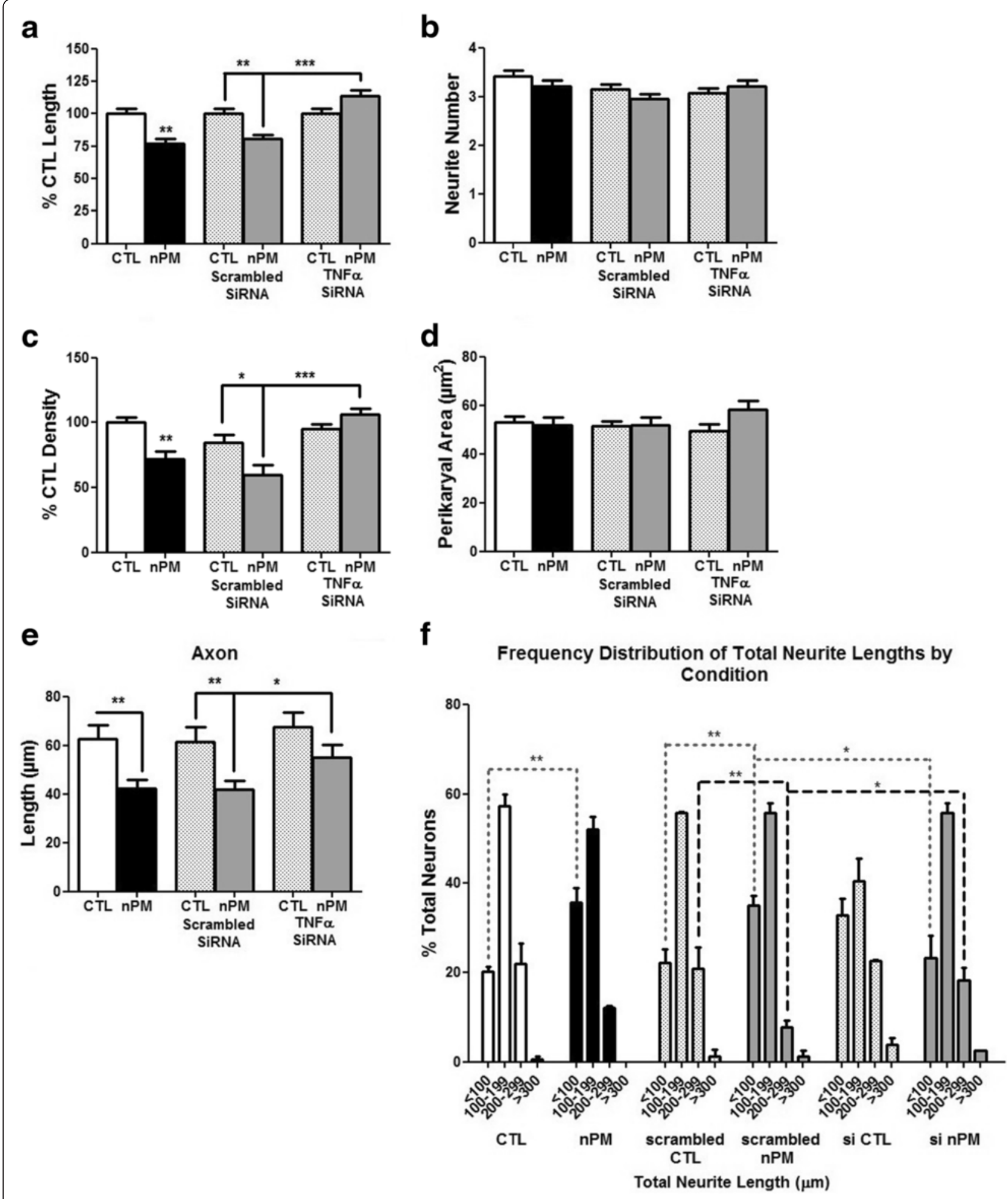

Fig. 5 TNFa siRNA rescued the inhibition of neurite outgrowth in $\mathrm{nPM}-\mathrm{CM}$. a CM from glia cultures transfected with siRNA to TNFa showed a rescue of total neurite outgrowth vs control cultures transfected with scrambled siRNA and treated with nPM $\left(*^{* *} p<0.01,{ }^{* * *} p<0.001\right.$; ANOVA with Tukey's post-test). b Neurite number, not altered by treatment. c Neurite-associated Blll-tubulin changed in parallel with total neurite length. $\mathbf{d}$ Neuronal perikaryal area, not altered by treatment. e Mean axon length shortening by nPM treatment was rescued with TNFa siRNA. $\mathbf{f}$ Neurons treated with nPM or scrambled siRNA + nPM mixed glial CM had shorter neurites (** $p<0.01$; two-way ANOVA with Tukey's post-test; avg. three experiments) 


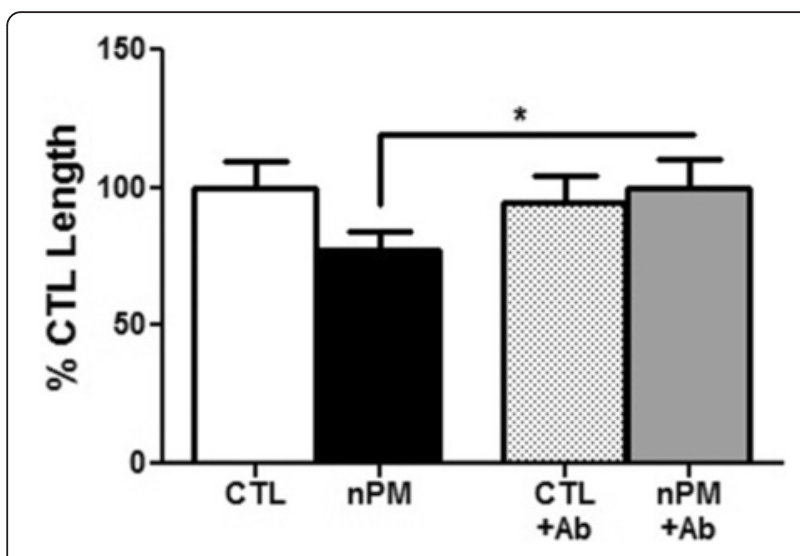

Fig. 6 Immunoneutralization of TNFa in CM rescued nPM inhibition of neurite outgrowth. Neurite outgrowth was inhibited by $25 \%$ in CM from nPM-exposed mixed glia (nPM-CM) $\left({ }^{*} p<0.05\right.$; ANOVA). TNFa immunoneutralization of $C M$ rescued neurite length posterior brain structures gives a rationale for using cerebral cortex glia as an experimental model for direct nPM exposure. Although astrocyte cell bodies were not detected in the $\mathrm{OE}$, there still may be a role of astrocytic TNF $\alpha$ in the OB which has deep neuronal projections caudally into the brain.

To develop our observations of OE dendritic shrinkage, we further analyzed mechanisms of neuronal responses to nPM with a model of primary cultures of mixed glia and neurons from the cerebral cortex. We extended our observation that CM from nPM-exposed mixed glia inhibited neurite outgrowth [10] by resolving cell type contributions. In subcultures from mixed glia, microglia contributed $60 \%$ of the TNF $\alpha$ in CM, consistent with the greater inhibition of neurite outgrowth by CM from microglia. Similarly, the microglial CM caused more inhibition of neurite outgrowth and neurite density than the astrocyte CM. A primary role of microglia in $\mathrm{nPM}$ responses is also consistent with the low abundance of GFAP-immunopositive cells or processes in the $\mathrm{OE}$, especially during development [49]. The precise mechanism of nPM uptake in cells is not well defined

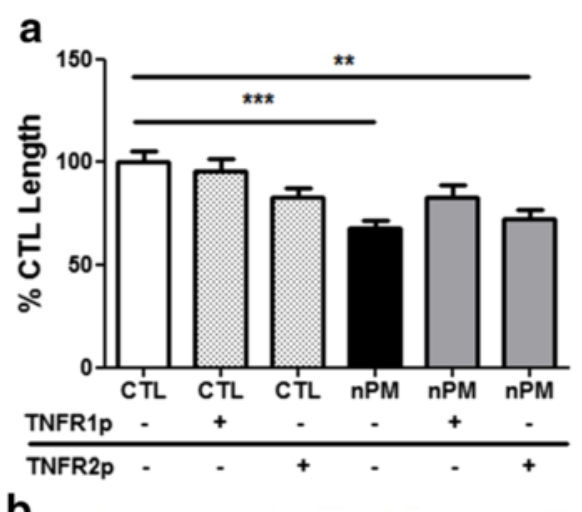

b

C
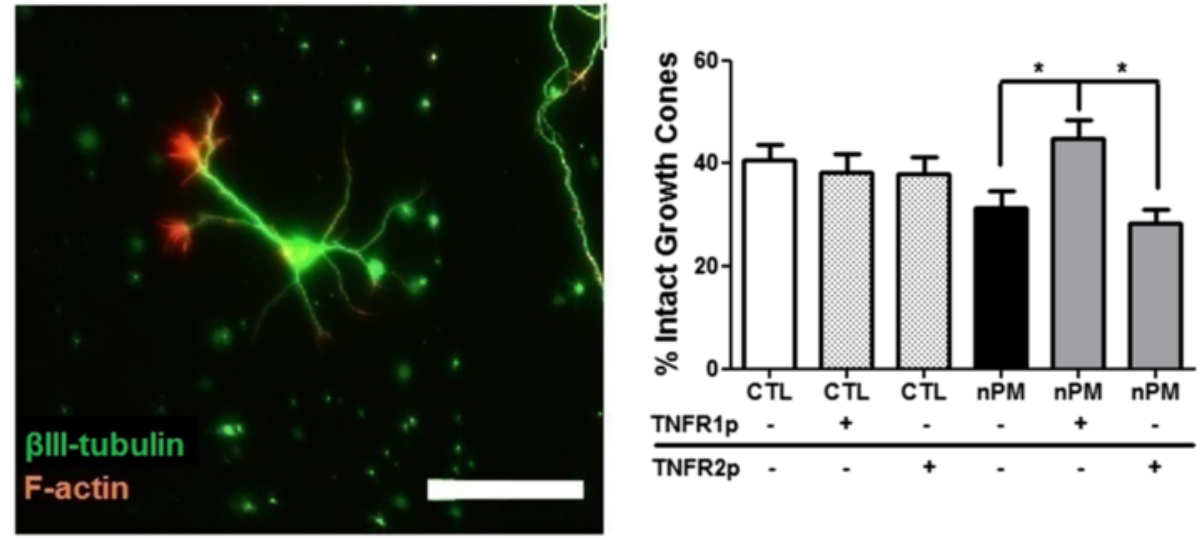

Fig. 7 TNFR1-blocking peptide rescued neurite outgrowth and growth cone collapse. a Pre-incubation of neurons with TNFR1-blocking peptide (TNFR1p) before exposure to nPM-CM restored neurite outgrowth to control levels. Pre-incubation with TNFR2-blocking peptide (TNFR2p) did not alter the nPM effect on neurite outgrowth. $\left({ }^{* *} p<0.01\right.$; ${ }^{* *} p<0.001$; ANOVA with Tukey's post-test; $\left.n=50\right)$. b Representative neuron with two intact and five collapsed growth cones. Intact growth cones have lamellipodia and multiple filopodia. Scale bar = $50 \mu \mathrm{m}$. c Blocking TNFR1 inhibited the nPM effect on percent intact growth cones per neuron ( ${ }^{*} p<0.05$; ANOVA) 
but could include phagocytosis [50] as well as direct diffusion [51].

The role of TNF $\alpha$ in neurite outgrowth inhibition was further defined by suppressing TNF $\alpha$ expression with siRNA, by immunoblockade of TNF $\alpha$, and by TNFR 1 blockade, all of which restored neurite outgrowth to control levels. The restoration of axonal length by TNF $\alpha$ immunoblockade is also consistent with enhanced axonal regeneration by TNF $\alpha$ blockade after injury [34]. Because these conditions did not consistently alter the total number of neurites or neuronal perikaryal size, they define an experimental model for effects of nPM on neuronal plasticity without major cell damage that could be useful for efficient screening of neuroprotective agents.

Several mechanisms may mediate the glial-derived TNF $\alpha$ influences on neurite outgrowth. Although TNF $\alpha$ has both cytosolic and transmembrane forms, we would not expect a significant role for transmembrane TNFa because the nPM-CM has negligible cell membrane content. Notably, of the two defined TNFRs, only blockade of TNFR1 rescued the nPM-CM effect. This specificity is consistent with the 20-fold higher affinity of TNFR1 $\left(K_{\mathrm{a}}\right)$ to soluble TNF $\alpha$ vs TNFR2 [52-54]. TNFR1 activation is associated with reduced neuronal differentiation, as well as apoptosis, whereas TNFR2 is associated with neuroprotection and survival [55]. Blocking TNFR1 may have improved neurite outgrowth by diminishing growth cone collapse (Fig. 7c) through reduction of CM TNFa signaling. The small GTPase RhoA mediates the TNF $\alpha$ inhibition of neurite outgrowth [24], but mechanisms from receptor signaling to neurite outgrowth inhibition are less defined. RhoA activation by TNF $\alpha$ can cause growth cone collapse and attenuate neurite outgrowth [24, 34, 56], but this process has not been directly linked to TNFR1/2 signaling [23].

\section{Conclusions}

These experimental findings suggest a role for TNFa induction by the nPM subfraction of PM2.5. We propose that TNF $\alpha$ from microglia-macrophage activation by nPM in inhaled air pollutants is a main mediator of neuroinflammation and neurodevelopmental impairments from airborne particulate pollution. Studies are needed to evaluate other TNF superfamily receptors and their relation to the glutamatergic changes observed in rodent models of air pollution [10, 11, 42]. Further fractionation of the nPM may resolve the role of the persistent free radicals in nPM [10] and specific chemical components in the heterogeneous nPM. Although these nPM fractions do not include ozone and other gases with cognitive epidemiological associations [2, 21], gaseous pollutants could still contribute to nPM neurotoxicity in the real world. Identifying the neurotoxic components in air pollution could prioritize environmental policy targets to minimize neurodegenerative activities in the urban air we must breathe.

\section{Abbreviations}

CM: conditioned media; CTL: control; DL: dendritic layer; GFAP: glial fibrillary acidic protein; Iba1: ionized calcium-binding adaptor molecule 1 and monocytic marker; IHC: immunohistochemistry; IL-1: interleukin 1; nPM: nano-sized particulate matter; PM: particulate matter; OB: olfactory bulb; OE: olfactory neuroepithelium; OSN: olfactory sensory neuron; TNFa: tumor necrosis factor alpha; TNFR: tumor necrosis factor receptor.

\section{Competing interests}

The authors declare that they have no competing interests.

\section{Authors' contributions}

HC carried out the experiments and data analysis and drafted the manuscript. DAD assisted with neuronal cultures. SH contributed to the collection, extraction, and chemical characterization of the nPM samples. CS contributed the nPM samples and designed the nPM collection. TEM participated in the design of studies and manuscript editing. CEF conceived the study, guided the experimental design, and edited the drafts. All authors read and approved the final manuscript.

\section{Acknowledgements}

This work was supported by grants from grants to CEF from the NIA (R21AG040753, R21AG040683); the Ellison Medical Foundation; and the USC Zumberge Research and Innovation Fund; SCEHSC Center grant P30ES007048.

\section{Author details}

${ }^{1}$ Davis School of Gerontology, University of Southern California, Los Angeles, CA 90089, USA. Viterbi School of Engineering, University of Southern California, Los Angeles, CA 90089, USA. ${ }^{3}$ USC Dornsife College, University of Southern California, Los Angeles, CA 90089, USA.

Received: 2 September 2015 Accepted: 11 January 2016

Published online: 26 January 2016

\section{References}

1. Ailshire JA, Crimmins EM. Fine particulate matter air pollution and cognitive function among older US adults. Am J Epidemiol. 2014;180:359-66.

2. Chen JC, Schwartz J. Neurobehavioral effects of ambient air pollution on cognitive performance in US adults. Neurotoxicol. 2009;30:231-9.

3. Gatto NM, Henderson WW, Hodis HN, St. John JA, Lurmann F, Chen JC, et al. Components of air pollution and cognitive function in middle-aged and older adults in Los Angeles. Neurotoxicol. 2014;40:1-7.

4. Jung CR, Lin YT, Hwang BF. Ozone, particulate matter, and newly diagnosed Alzheimer's disease: a population-based cohort study in Taiwan. J Alzheimer's Dis. 2015:44:573-84.

5. Weuve J, Puett RC, Schwartz J, Yanosky JD, Laden F, Grodstein F. Exposure to particulate air pollution and cognitive decline in older women. Arch Intern Med. 2012;172:219-27.

6. Volk HE, Lurmann F, Penfold B, Hertz-Picciotto I, McConnell R. Traffic-related air pollution, particulate matter, and autism. JAMA Psychiatry. 2013;70:71-7.

7. Calderón-Garcidueñas L, Torres-Jardon R, Kulesza RJ, Park SB, D'Angiulli A. Air pollution and detrimental effects on children's brain. The need for a multidisciplinary approach to the issue complexity and challenges. Front Hum Neurosci. 2014;8:613.

8. Levesque S, Taetzsch T, Lull ME, Kodavanti U, Stadler K, Wagner A, et al. Diesel exhaust activates and primes microglia: air pollution, neuroinflammation, and regulation of dopaminergic neurotoxicity. Environ Health Perspect. 2011;1198:1149-55.

9. Genc S, Zadeoglulari Z, Fuss SH, Genc K. The adverse effects of air pollution on the nervous system. J Toxicol. 2012;2012:1-23.

10. Morgan TE, Davis DD, Iwata N, Tanner JM, Snyder D, Ning Z, et al. Glutamatergic neurons in rodent models respond to nanoscale particulate urban air pollutants in vivo and in vitro. Env Health Perspect. 2011;119:1003-9.

11. Davis DA, Akopian G, Walsh JP, Sioutas C, Morgan TE, Finch CE. Urban air pollutants reduce synaptic function of CA1 neurons via an NMDA/NO pathway in vitro. J Neurochem. 2013;127:509-19.

12. Zhang H, Liu H, Davies KJ, Sioutas C, Finch CE, Morgan TE, et al. Nrf2regulated phase $\|$ enzymes are induced by chronic ambient nanoparticle 
exposure in young mice with age-related impairments. Free Radic Biol Med. 2012:52:2038-46.

13. Kleinman MT, Araujo JA, Nel A, Sioutas C, Campbell A, Cong PQ, et al. Inhaled ultrafine particulate matter affects CNS inflammatory processes and may act via MAP kinase signaling pathways. Toxicol Lett. 2008;178:127-30.

14. Block ML, Calderón-Garcidueñas L. Air pollution: mechanisms of neuroinflammation and CNS disease. Trends Neurosci. 2009;32:506-16.

15. Calderón-Garcidueñas L, Engle R, Mora-Tiscareño A, Styner M, Gómez-Garza $\mathrm{G}$, Zhu H, et al. Exposure to severe urban air pollution influences cognitive outcomes, brain volume and systemic inflammation in clinically healthy children. Brain Cogn. 2011;77:345-55.

16. Chen JC, Wang X, Wellenius G, Serre M, Driscoll I, Casanova R, et al. Ambient air pollution and neurotoxicity on brain structure: evidence from Women's Health Initiative Memory study. Ann Neurol. 2015;78:466-76.

17. Li N, Sioutas C, Cho A, Schmitz D, Misra C, Sempf J, et al. Ultrafine particulate pollutants induce oxidative stress and mitochondrial damage. Environ Health Perspect. 2003;111:455-60.

18. Gillespie P, Tajuba J, Lippmann M, Chen LC, Veronesi B. Particulate matter neurotoxicity in culture is size-dependent. Neurotoxicol. 2013;36:112-7.

19. Oberdörster G, Sharp Z, Atudorei V, Elder A, Gelein R, Kreyling W, et al. Translocation of inhaled ultrafine particles to the brain. Inhal Toxicol. 2004; 16:437-45.

20. Elder A, Gelein R, Silva V, Feikert T, Opanashuk L, Carter J, et al. Translocation of inhaled ultrafine manganese oxide particles to the central nervous system. Environ Health Perspect. 2006;114:1172-8.

21. Wu YC, Lin YC, Yu HL, Chen JH, Chen TF, Sun Y, et al. Association between air pollutants and dementia risk in the elderly. DADM. 2015;1:220-28.

22. Allen JL, Liu X, Pelkowski S, Palmer B, Conrad K, Oberdörster G, et al. Early postnatal exposure to ultrafine particulate matter air pollution: persistent ventriculomegaly, neurochemical disruption, and glial activation preferentially in male mice. Environ Health Perspect. 2014;122:939-45.

23. Mathew SJ, Haubert D, Kronke M, Leptin M. Looking beyond death: a morphogenetic role for the TNF signalling pathway. J Cell Sci. 2009;122: 1939-946.

24. Neumann H, Schweigreiter R, Yamashita T, Rosenkranz K, Wekerle H, Barde YA. Tumor necrosis factor inhibits neurite outgrowth and branching of hippocampal neurons by a Rho-dependent mechanism. J Neurosci. 2002;22:854-62.

25. Wójciak-Stothard B, Entwistle A, Garg R, Ridley AJ. Regulation of TNF-a-induced reorganization of the actin cytoskeleton and cell-cell junctions by Rho, Rac, and Cdc42 in human endothelial cells. J Cell Physiol. 1998;176:150-65.

26. Bourhis ML, Rimbaud S, Grebert D, Congar P, Meunier N. Endothelin uncouples gap junctions in sustentacular cells and olfactory ensheathing cells of the olfactory mucosa. Eur J Neurosci. 2014;40:2878-887.

27. Ronnett GV, Leopold D, Cai X, Hoffbuhr KC, Moses L, Hoffman EP, et al. Olfactory biopsies demonstrate a defect in neuronal development in Rett's Syndrome. Ann Neurol. 2003;54:206-18.

28. Misra C, Kim S, Shen S, Sioutas C. A high flow rate, very low pressure drop impactor for inertial separation of ultrafine from accumulation mode particles. J Aerosol Sci. 2002;33:735-52.

29. Saffari A, Daher N, Shafer MM, Schauer JJ, Sioutas C. Seasonal and spatial variation in reactive oxygen species activity of quasi-ultrafine particles (PM 0.25 ) in the Los Angeles metropolitan area and its association with chemical composition. Atmos Environ. 2013;79:566-75.

30. Ning Z, Geller MD, Moore KF, Sheesley R, Schauer JJ, Sioutas C. Daily variation in chemical characteristics of urban ultrafine aerosols and inference of their sources. Environ Sci Technol. 2007:41:6000-6.

31. Daher N, Hasheminassab S, Shafer MM, Schauer JJ, Sioutas C. Seasonal and spatial variability in chemical composition and mass closure of ambient ultrafine particles in the megacity of Los Angeles. Environ Sci Process Impacts. 2013;15:283-95.

32. Rozovsky I, Finch CE, Morgan TE. Age-related activation of microglia and astrocytes: in vitro studies show persistent phenotypes of aging, increased proliferation, and resistance to down-regulation. Neurobiol Aging. 1998;19:97-103.

33. Yamamoto H, Demura T, Morita M, Banker GA, Tanii T, Nakamura S. Differential neurite outgrowth is required for axon specification by cultured hippocampal neurons. J Neurochem. 2012;123:904-10.

34. Kato K, Liu H, Kikuchi S, Myers RR, Shubayev VI. Immediate anti-tumor necrosis factor-alpha (etanercept) therapy enhances axonal regeneration after sciatic nerve crush. J Neurosci Res. 2010;88:360-68.
35. Morgan TE, Laping NJ, Rozovsky I, Oda T, Hogan TH, Finch CE, et al. Clusterin expression by astrocytes is influenced by transforming growth factor beta 1 and heterotypic cell interactions. J Neuroimmunol. 1995;58:101-10.

36. Stone DJ, Rozovsky I, Morgan TE, Anderson CP, Hajian H, Finch CE. Astrocytes and microglia respond to estrogen with increased apoE mRNA in vivo and in vitro. Exp Neurol. 1997;143:313-8.

37. Sunyer J, Esnaola M, Alvarez-Pedrerol M, Forns J, Rivas I, López-Vicente M, et al. Association between traffic-related air pollution in schools and cognitive development in primary school children: a prospective cohort study. PLoS Med. 2015; doi:10.1371/journal.pmed.1001792

38. Woodward N, Finch CE, Morgan TE. Traffic-related air pollution and brain development. AIMS Environ Sci. 2015;2:353-73.

39. Davis DA, Bortolato M, Godar SC, Sander TK, Iwata N, Pakbin P, et al. Prenatal exposure to urban air nanoparticles in mice causes altered neuronal differentiation and depression-like responses. PLoS One. 2013b; doi:10.1371/journal.pone.0064128

40. Campbell A, Oldham M, Becaria A, Bondy SC, Meacher D, Sioutas C, et al. Particulate matter in polluted air may increase biomarkers of inflammation in mouse brain. Neurotoxicol. 2005;26:133-40.

41. Campbell A, Daher N, Solaimani P, Mendoza K, Sioutas C. Human brain derived cells respond in a type-specific manner after exposure to urban particulate matter. Toxicol In Vitro. 2014:28:1290-295.

42. Wen-Shwe TT, Mitsushima D, Yamamoto S, Fukushima A, Funabashi T, Kobayashi T, et al. Changes in neurotransmitter levels and proinflammatory cytokine mRNA expressions in the mice olfactory bulb following nanoparticle exposure. Toxicol Appl Pharm. 2008;226:192-98.

43. Gelbard HA, Dzenko KA, Wang L, Talley A, James H, Epstein L. HIV-1-derived neurotoxic factors: effects on human neuronal cultures. In: Major EO, Levy JA, Schoenberg D, editors. Technical advances in AIDS research in the human nervous system. New York: Plenum Press; 1995. p. 61-72.

44. Abd-El-Basse EM. Pro-inflammatory cytokine; tumor necrosis factor alpha (TNF-a) inhibits astrocytic support of neuronal survival and neurites outgrowth. Adv Biosci Biotechnol. 2013;4:73-80.

45. Bond JA, Harkema JR, Russell VI. Regional distribution of xenobiotic metabolizing enzymes in respiratory airways of dogs. Drug Metab Dispos. 1988;16:116-24.

46. Longo V, Ingelman-Sundberg M, Amato G, Salvetti A, Gervasi PG. Effect of starvation and chlormethiazole on cytochrome P450s of rat nasal mucosa. Biochem Pharmacol. 2000;59:1425-32.

47. Turner JH, Liang KL, May L, Lane AP. Tumor necrosis factor alpha inhibits olfactory regeneration in a transgenic model of chronic rhinosinusitisassociated olfactory loss. Am J Rhinol Allergy. 2010;24:336-40.

48. Oberdörster G, Elder A, Rinderknecht A. Nanoparticles and the brain: cause for concern? J Nanosci Nanotechno. 2009;9:4996-5007.

49. Vincent AJ, West AK, Chuah MI. Morphological and functional plasticity of olfactory ensheathing cells. J Neurocytol. 2005;34:65-80.

50. Xia T, Kovochich M, Brant J, Hotze M, Sempf J, Oberley T, et al. Comparison of the abilities of ambient and manufactured nanoparticles to induce cellular toxicity according to an oxidative stress paradigm. Nano Lett. 2006;6:1794-807.

51. Geiser M, Rothen-Rutishauser B, Kapp N, Schürch S, Kreyling W, Schulz H, et al. Ultrafine particles cross cellular membranes by nonphagocytic mechanisms in lungs and in cultured cells. Environ Health Perspect. 2005; 113:1555-60.

52. Ksontini R. Revisiting the role of tumor necrosis factor alpha and the response to surgical injury and inflammation. Arch Surg. 1998;133:558-67.

53. Cabal-Hierro L, Lazo PS. Signal transduction by tumor necrosis factor receptors. Cell Signal. 2012;24:1297-305.

54. Grell M, Wajant H, Zimmermann G, Scheurich P. The type 1 receptor (CD120a) is the high-affinity receptor for soluble tumor necrosis factor. Proc Natl Acad Sci. 1998;95:570-5.

55. Chen Z, Palmer TD. Differential roles of TNFR1 and TNFR2 signaling in adult hippocampal neurogenesis. Brain Behav Immun. 2013;30:45-53.

56. Wu KY, Hengst U, Cox $\sqcup$, Macosko EZ, Jeromin A, Urquhart ER, et al. Local translation of RhoA regulates growth cone collapse. Nature. 2005;436:1020-024. 